\title{
On the Importance of Sanitary Sewer Overflow on the Total Discharge of Microplastics from Sewage Water
}

\author{
Christian Baresel*, Mikael Olshammar \\ IVL Swedish Environmental Research Institute, Stockholm, Sweden \\ Email: *christian.baresel@ivl.se
}

How to cite this paper: Baresel, C. and Olshammar, M. (2019) On the Importance of Sanitary Sewer Overflow on the Total Discharge of Microplastics from Sewage Water. Journal of Environmental Protection, 10, 1105-1118.

https://doi.org/10.4236/jep.2019.109065

Received: July 4, 2019

Accepted: September 2, 2019

Published: September 5, 2019

Copyright $\odot 2019$ by author(s) and Scientific Research Publishing Inc. This work is licensed under the Creative Commons Attribution International License (CC BY 4.0).

http://creativecommons.org/licenses/by/4.0/

\begin{abstract}
The paper provides an investigation and understanding of the significance of various wastewater flows on microplastics retainment and emission to the environment. WWTPs and sewer overflows as an important pathway of microplastics to the environment are assessed by considering the removal of microplastics in WWTPs with different treatment processes and several sewer overflow types and their contribution to microplastic loads to recipients. On the example of the Baltic Sea basin, presented results indicate a considerable discharge of microplastic from WWTPs despite the relatively good overall removal efficiency. Results show that the discharge of microplastics from sewer overflows can be in the same magnitude as from treated wastewater although the total flow is much lower than that of treated wastewater. Sewer overflow events frequently occur and are expected to increase due to climate change and urbanization, unless infrastructure is adapted. At the same time, sewer overflows are often neglected in conventional wastewater handling.
\end{abstract}

\section{Keywords}

Microplastics, Wastewater Treatment, Sanitary Sewer Overflow, Emissions, Baltic Sea Basin

\section{Introduction}

The problem with microplastic pollution of water environments has been recognized as one factor for the declining water quality globally and has also been pointed out as one potential factor for the observed biodiversity decline worldwide [1] [2] [3]. Several regional and global actions to address the problem of microplastic have been proposed, e.g. by the United Nations Conference on 
Sustainable Development in Rio+20 in 2012, which particularly mentioned the threat of plastics for the marine environment. Even if the key to reducing microplastics inputs to the environment is at the source, a ban of plastics in general such as done for other pollutants is not a realistic way forward as plastics have become essential for our modern society mainly because of their advantageous properties such as its durability. Even improved management of plastic waste including recycling and proper disposal will not prevent plastics to end up in the aquatic environment to some extent.

Microplastics, commonly defined as $<5 \mathrm{~mm}$ in diameter, have their origin mainly from the fragmentation of larger plastic particles often termed as secondary microplastics [1]. Intentionally produced microplastics such as abrasives in personal care products or for industrial purposes are termed primary microplastics.

The potential impacts of microplastics on ecosystems are difficult to quantify. This is partly because of challenges to attribute impacts of microplastics from field observations and laboratory-based experimental are therefore often used to investigate physical effects. Even more difficult to quantify are chemical effects of microplastics as they may decay and because they may be carriers of various pollutants. Lipophilic organic contaminants, for example, can be absorbed by plastics and then taken up by animals. A clear causal relationship is then difficult to quantify. However, even though current knowledge assessing the risk from microplastics is insufficient, several studies indicate effects on living organisms caused by microplastics (e.g., [1] [4]-[10]) while other studies suggest similar effects as for natural particles [11]. Furthermore, microplastics included additives and adsorbed persistent organic pollutants on the surface of microplastics may pose an issue [12] [13] [14] [15].

There are several studies postulating municipal wastewater treatment plants (WWTPs) as one of the major pathways of microplastics to the environment [16] [17] [18] [19] [20]. There are also a great number of studies that report an efficient removal of microplastics in WWTPs [18] [21]-[26]. The vast volume of wastewater treated, however, implies significant amounts of microplastics entering the environment even modest amounts of microplastics in the WWTPs effluent. There are few studies on the significance of untreated wastewater released into recipients during different conditions such as technical failures, capacity limitations at the WWTPs or the sewer system. [23] and [27] indicated that sewer overflows may play a significant contribution to the total load of microplastics to the environment. However, so far, no attempts have been made to look more into this aspect.

The aim of this article is to provide a holistic investigation and understanding of the significance of various wastewater flows on microplastics retainment and emission to the environment. WWTPs and sewer overflows as an important pathway of microplastics to the environment are assessed by considering the removal of microplastics in WWTPs with different treatment processes and sev- 
eral sewer overflow types and their contribution to microplastic loads to recipients. With the example of the Baltic Sea basin, the presented findings could help to improve mitigation strategies to reduce the problem on microplastics in the aquatic environment.

\section{Material and Methods}

Wastewater as a source for microplastics to the Baltic Sea has been investigated by means of 1) quantification of microplastic discharge from WWTPs to the Baltic Sea including the compilation of wastewater treatment practices and technologies; and 2) estimation of sanitary sewer overflow (SSO) as a source for microplastics to the Baltic Sea. Only net loads of microplastics on the Baltic Sea from WWTPs and SSOs were considered and as such no retention is considered in the presented study.

\subsection{WWTPs in the Baltic Sea Basin}

The quantification of microplastic discharge from WWTPs and SSO to the Baltic Sea is based on a compilation of exiting information from publicly accessible databases including [28] [29] [30] [31]. Because [28] includes more data on WWTPs than the [29] database, the study uses [28] as main data source complemented by data from [29] mainly for Russia and Belarus, which are not included in [28]. As the different data sources are not using some reporting format and plant identification number, also other data such as e.g. information about WWTP location coordinates have been used to merge necessary information. Furthermore, more detailed data available from Swedish and Danish databases were incorporated in the study. The total number of unique WWTPs in the study is 3526 . Within the project, a specific survey has been developed and sent to project members and other relevant organizations to retrieve missing information about mainly total load on WWTPS, treatment technology and information about overflow events.

WWTPs loads used in this study are defined as population equivalent or unit per capita loading (pe) and corresponds to the amount of degradable organic material with a biochemical oxygen consumption of 70 grams of dissolved oxygen per day over seven days (BOD7, used e.g. in Sweden) or a biochemical oxygen consumption of 60 grams of dissolved oxygen per day over five days (BOD5, used e.g. in Poland).

Reported data quality and quantity varies significantly between the various Baltic Sea countries which is illustrated in Figure 1. All plants in the database are situated in the Baltic Sea Catchment (HELCOM basin definition). Many of the WWTPs included in the different databases were not considered as necessary basic data on flows was not available, facilities have been closed or receiving wastewater is diverted to other WWTPs.

Data quality on WWTP loads varies significantly with some countries not providing any data on water flows $\left(\mathrm{m}^{3} /\right.$ year) or total load (pe). As the WWTP 


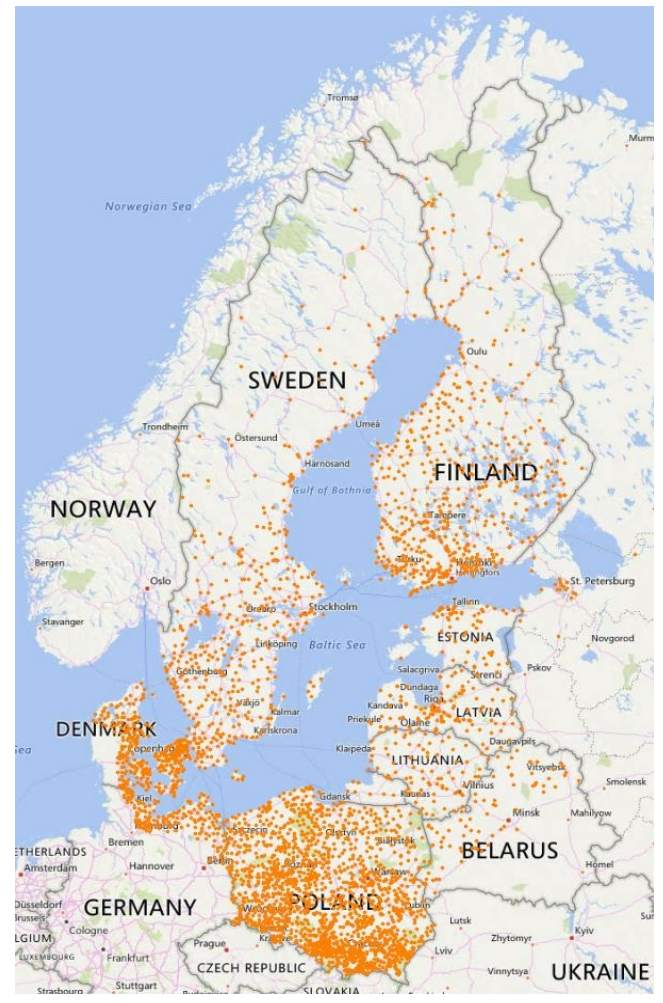

Figure 1. Distribution of WWTPs in the Baltic Sea basin with reported data available in public databases.

in- or outflow of wastewater is an important parameter for the calculation of microplastic discharge, water flows were calculated for WWTPs without such data. The estimation of water flow was based on an average annual flow of 125 $\mathrm{m}^{3}$ per personal equivalent, which is derived from Swedish average flows to WWTPs [32] and data on German WWTP inflow [33]. This flow includes generated sewage water from households and industries but also other water flowing into sewer systems, i.e. surface runoff and groundwater.

For some countries, e.g. Germany and Estonia, reported flow data is judged to be incomplete or faulty as reported data varies outside common and expected ranges. Both reported flows and calculations of flows based on reported connected persons for WWTPs without flow data give annual sewage flow to WWTPs as low as $20 \mathrm{~m}^{3} /(\mathrm{pe}, \mathrm{yr}$ ) on average, which may be considered impossible to achieve even in completely new separated sewer systems and water saving installations in households. For a limited area, such average flows may be realistic but for a complete sewer connected to a WWTP, such areas do to the authors best knowledge not exist in the considered region of interest. However, reported flows were used in this study but a more throughout assessment of these data is recommended as actual flows may be significant higher and thus also related emissions in general and as calculated and reported here. In the case of Poland, reported flow data is erroneous as they are unrealistically low. Flow data for these WWTPs have been calculated based on the reported load and average flow assumptions. 


\subsection{Removal Efficiencies of WWTPs}

To assess the removal efficiency of each WWTP, reported data on used treatment technologies from the data sources described has been combined with load data and related studies on treatment efficiency for microplastics using different technologies (e.g. [18] [20] [25] [26] [34] [35]). Based on these studies, average removal efficiencies have been defined in this study according to Table 1.

\subsection{Microplastic Concentrations}

The quantification of microplastic discharge from WWTPs to the Baltic Sea is based on the reported and calculated flows to considered WWTPs and the specific treatment available at each specific facility. Two different sets of microplastic concentrations and weights have been used in the study as shown in Table 2. First, derived data from the project groups own microplastic analyses during several years and reported in several studies (e.g. [23] [34] [36] [37]) has been used. These measurements exclude non-synthetic fibres and consider only microplastics $>20 \mu \mathrm{m}$. The other data set is based on recently reported data by [25] and [38] and included measurements of microplastics down to the size of $10 \mu \mathrm{m}$. A WWTP-specific adjustment of microplastics concentrations based on reported BOD-loads have not been performed, as microplastics concentrations do generally not follow traditional pollutant indications such as BOD, Total nitrogen (TN) or Total phosphorous (TP). The use of two different data sets is motivated because recently reported data differs significantly from the project groups own quantifications. Especially reported concentrations and weights by [38] for Danish WWTPs diverge significantly with extremely higher particle counts and much smaller particle weights. The authors themselves recognized this deviation and discuss possible explanations including the smaller particle size included. Their results indicate that $90 \%$ of the particle sizes in raw wastewater are about $100 \mu \mathrm{m}$ (and $91 \mu \mathrm{m}$ in treated wastewater). However, a clear reason for these significant deviations is not provided and therefore two separate data sets are used in this study to investigate the impact of reported data.

Both sets of data sources have been assess and minimum, median and maximum values defined. However, these values are not based on strict statistical methods but rather the best possible estimate of these as pure Statistical methods are difficult to apply. This is mainly explained by the lack of standardization

Table 1. WWTP treatment techniques and average microplastics removal efficiency [\%].

\begin{tabular}{cc}
\hline Treatment technique & Average removal efficiency for microplastics [\%] \\
\hline Primary treatment & 85 \\
Secondary treatment & 90 \\
Tertiary treatment & 95 \\
Sand filter & 97 \\
Microfiltration & 98 \\
\hline
\end{tabular}


Table 2. Microplastics concentrations and weight in WWTPs inflow.

\begin{tabular}{cc}
\hline Microplastics concentration, weight & Value \\
\hline Data source 1: Project groups own verified measurements \\
microplastics $>20 \mu \mathrm{m}$
\end{tabular}

in microplastic analyses leading to high variation of methods used in sampling, preparation, analyses and reporting of microplastics. This is a known problem in the field of microplastics research and especially when comparing various studies [1]. However, the current study has still set minimum, median and maximum values based on available data to examine the discharge of microplastics and the range of such discharges.

\subsection{Sewer Overflows}

Sanitary sewer overflows (SSO) are a condition where untreated wastewater is discharged from a sanitary sewer into the environment, normally due to lack of process or hydraulic capacity. In combined sewer systems, commonly in urban areas, surface water runoff, domestic sewage and industrial wastewater is jointly transported to the WWTP for treatment. Periods of heavy rainfall or snowmelt may then cause sewer overflows, where untreated excess capacity is discharged to nearby streams, rivers, and other waterbodies.

This study focusses on the three common types of SSO, i.e. technical SSO, weather event SSO and SSO at WWTPs. Technical SSO describe sewer overflows caused by technical failures of pump stations or other sewer installations. This type of SSO is also common during reconstruction of sewer infrastructure. Technical SSO occur at no specific flow conditions such as the other two types of SSO.

Weather event SSOs may be characterized as "real" SSOs as they appear in the sewer network when the hydraulic capacity of the sewer is exceeded. This may be the case e.g. at heavy rainfall or snowmelt. Untreated wastewater is then discharged directly to the recipient. While concentrations of traditional sewage pollutants such as organic matter, nitrogen and phosphorous normally much smaller in the overflow water due to dilution of wastewater during these events, this is not necessarily the case for microplastics as one of the main sources of 
microplastics is stormwater causing this type of SSOs (e.g. [23] [37] [39]). [23] and [27] indicated significant higher microplastic concentrations in sewage during stormwater events. In this study the microplastic concentrations in sewage have been set to 5 times the normal concentrations. However, this only applies to weather event SSOs and SSO at WWTPs as these only occur during weather related events such as heavy rain or snowmelt.

The last category of considered SSOs comprises overflows at WWTPs due to a hydraulic capacity limitation of the WWTP but where the discharged water undergoes at least a partial treatment. As this partial treatment often targets particulate phosphorous, a good removal effect is also achieved on microplastics. As studies on the removal efficiency of microplastics in partial overflow treatment are not available, the removal efficiency for microplastics of $80 \%$ was assumed in this study.

There is no data available in the databases on SSO events and most countries have no active monitoring of such events whatsoever, which implies that even the study's own survey was not able to gather any usable data on the overflow quantities in different countries. As Sweden has been one of the countries that has tried to focus on the SSO during recent years, some data on SSO magnitudes could be used and applied as a best estimate for other countries as well. It is important to point out that even the used Swedish data [40] [41] is not complete and reporting is limited by understanding of various SSO events. Technical SSO are for example often reported as normal SSO events. Overflows at WWTPs are often not characterized regarding if a partial treatment of the water by e.g. chemical precipitation, is applied or if the wastewater is discharge to the recipient without any treatment. Based on few reported data, the study defined the annual overflow for the various SSO-types as fraction of the total WWTP inflow. Specifically, this implies that technical SSO are estimated to $0.4 \%$, weather event SSO to $1.5 \%$ and SSO at WWTPs to $0.4 \%$, respectively.

\section{Results and Discussion}

\subsection{Quantification of Microplastic Discharge from WWTPs}

The evaluation of WWTPs in the Baltic Sea basin indicated that all considered WWTPs have at least a secondary treatment installed and thus an efficient removal of microplastics in WWTPs by $85 \%$ is given on average. This is true except for some WWTPs especially in Russia (including Kaliningrad) were only primary treatment or no treatment at all is reported. In such cases, information about phosphorous removal efficiencies has been used to define the overall treatment efficiency. For Belarus, secondary treatment has been assumed for all plants as no other information than loads were available. About 1690 WWTPs in the basin have an extended treatment with phosphorous removal. 74 WWTPs have sand filtration as final polishing step but only 14 WWTP use microfiltration (MF) to treat their wastewater. Reported data on WWTPs treatment configuration, however, is of varying quality. In addition, a different understanding in 
the various countries of what treatment technologies that are included in e.g. primary, secondary and tertiary treatment may imply uncertainties in reported data. Sand filtration, for example, is considered as natural part of phosphorus removal or tertiary treatment by some WWTPs, while it is not for others.

The average microplastic removal efficiency of all considered WWTPs is determined to $93 \%$ based on the reported treatment processes used. While most countries have a better removal efficiency, Lithuania archives only an average removal efficiency of $86 \%$ and Russia (incl. Kaliningrad) and Belarus 90\%, which lowers the total average. It must be noted that the removal efficiencies in Russian and Belarus WWTPs was estimated based on phosphorous removal data or in some cases assumed to be at least secondary. Thus, actual removal efficiency may be lower than reported here.

Considering the total annual amount treated wastewater of $>8900 \mathrm{Mm}^{3}$ discharged to the Baltic Sea from these WWTPs, and accounting for each treatment facilities' removal efficiency for microplastics, a total microplastic discharge to the Baltic Sea from WWTPs is calculated to $13,700 \times 10^{9}$ particle/yr and $48,000 \times$ $10^{9}$ particle/yr as median for data set 1 respective 2 (see Table 3, I and V). Calculated total particle weight is $90 \mathrm{t} / \mathrm{yr}$ and $1.7 \mathrm{t} / \mathrm{yr}$, respectively. Considering min and max values, min particle counts indicate significant differences in the calculated results for the two data sources (Table 3 ).

Reported microplastic discharges from WWTPs according to Table 3 indicate an enormous span of possible outcomes depending on which initial measurements are used. Comparable studies on microplastics in WWTPs are still rare because of the absence of sampling, preparation and analyses standards. This also partly explains the high variations in reported values. The use of the two data sets in this study can hopefully provide a better understanding on the impact of initial microplastic analyses on total discharge quantifications. Further, the weight of microplastics is still difficult to measure with certainty. Results provided in Table 3 may still give a good indication. However, they must be handled with care as microplastics consist of many different plastics and depending on actual sources the composition in the wastewater can vary significantly between WWTPs.

A discharge of about 90 ton/yr via WWTP effluent to recipients flowing into the Baltic Sea as indicated in Table 3 (I) can be compared with reported values by [23] for the total microplastic discharge from Swedish WWTPs of $4.7-42$ ton/yr. Calculated discharge of microplastic based on the second data source comprised a much wider range with significant maximum discharge while the median discharge both in particle number and weight seems rather underestimated.

Considering the mentioned uncertainties in reported flow data for e.g. Germany and other countries, actual discharge of microplastic may even be higher. This is because reported flow data is assessed to be significantly lower than expected and for similar regions. 
Table 3. Microplastic discharge to the Baltic Sea basin from WWTPs and Sanitary Sewer Overflows (SSO).

\begin{tabular}{|c|c|c|c|c|c|}
\hline \multirow[b]{2}{*}{$\mathrm{Nr}$} & \multicolumn{5}{|c|}{ Microplastic discharge } \\
\hline & \multicolumn{2}{|l|}{ WWTP \& SSO } & [109 particle/yr] & [ton/yr] & [\%] \\
\hline \multicolumn{6}{|c|}{ Data source 1: Project group measurements $(\mathrm{MP}>20 \mu \mathrm{m})$} \\
\hline & & $\min$ & 6,950 & 46 & \\
\hline \multirow[t]{3}{*}{ I } & WWTP & median & 13700 & 90 & 42.7 \\
\hline & & $\max$ & 33,800 & 223 & \\
\hline & & $\min$ & 450 & 3 & \\
\hline \multirow[t]{3}{*}{ II } & Technical SSO & median & 900 & 6 & 2.8 \\
\hline & & $\max$ & 2200 & 15 & \\
\hline & & $\min$ & 8500 & 56 & \\
\hline \multirow[t]{3}{*}{ III } & Weather event SSO & median & 16,800 & 110 & 52.4 \\
\hline & & $\max$ & 41,400 & 273 & \\
\hline & & $\min$ & 340 & 2.2 & \\
\hline \multirow[t]{5}{*}{ IV } & $\begin{array}{l}\text { SSO treatment } \\
\text { at WWTP }\end{array}$ & median & 670 & 4.4 & 2.1 \\
\hline & & $\max$ & 1650 & 11 & \\
\hline & & & & & $\Sigma 100$ \\
\hline & Data source 2: & Dther mea & ements (MP $>10$ & & \\
\hline & & $\min$ & 8030 & 0.3 & \\
\hline \multirow[t]{3}{*}{$\mathrm{V}$} & WWTP & median & 48,000 & 1.7 & 42.7 \\
\hline & & $\max$ & $5,350,000$ & 187.3 & \\
\hline & & $\min$ & 520 & 0 & \\
\hline \multirow[t]{3}{*}{ VI } & Technical SSO & median & 3150 & 0.1 & 2.8 \\
\hline & & $\max$ & 350,000 & 12.2 & \\
\hline & & $\min$ & 9800 & 0.3 & \\
\hline \multirow[t]{3}{*}{ VII } & Weather event SSO & median & 59,000 & 2.1 & 52.4 \\
\hline & & $\max$ & $6,560,000$ & 229.6 & \\
\hline & & $\min$ & 390 & 0 & \\
\hline \multirow[t]{3}{*}{ VIII } & $\begin{array}{l}\text { SSO treatment } \\
\text { at WWTP }\end{array}$ & median & 2360 & 0.1 & 2.1 \\
\hline & & $\max$ & 262,400 & 9.2 & \\
\hline & & & & & $\Sigma 100$ \\
\hline
\end{tabular}

\subsection{Quantification of Microplastic Discharge from Sanitary Sewer Overflows (SSO)}

The total amount of sewage discharged to recipients from sanitary sewer overflows (SSO) in the Baltic Sea basin was estimated to $200 \times 10^{6} \mathrm{~m}^{3}$ annually, i.e. $2.3 \%$ of the total sewage flow to all considered WWTPs. Of this total SSO-discharge, technical SSO and SSO after treatment at WWTPs account annually for about 35 
$\times 10^{6} \mathrm{~m}^{3}$ each. Weather event SSO accounts for the major part with $>130 \times 10^{6}$ $\mathrm{m}^{3}$ annually.

With the considered microplastic concentrations for the different SSO-types, total microplastic discharges are calculated and presented in Table 3 (row II-IV and VI-VIII). The calculation of microplastic discharge to recipients from sanitary sewer overflows (SSO) in the Baltic Sea basin indicate that more than half of the total discharge of microplastics originating from sewage may come from SSOs. While technical SSO and SSO after treatment at WWTPs together only contribute with less than 5\%, weather event SSO alone may account for $>50 \%$ of total discharges. This even though they only stand for $1.5 \%$ of the total sewage flow to WWTPs in the basin.

The results presented in Table 3 further indicate that the total contribution of the different pathways, i.e. WWTPS and different SSO-types, is unaffected of the dataset used as microplastics concentrations changes for all pathways simultaneously. Total microplastic numbers and masses are of course changed depending on the data set used in the calculations.

Even if same microplastic concentrations in sewage are assumed during weather event SSO as for normal flow conditions, weather event SSO would contribute with more than $18 \%$ of the total microplastic discharge.

Considering the inconsistent data reported for e.g. German WWTPs, actual weather event SSO may even be higher and thus would influence the total contribution of such events on total microplastic discharge. Overall, technical SSO contribute only with minor microplastic amounts as the extent of these events is limited and assumed to happen mostly under normal flow conditions. However, technical SSO become more important (from $2.8 \%$ to $5 \%$ ) if same microplastic concentrations are considered during weather event SSO. SSO after treatment at WWTPs, where the overflow is partly treated, accounts for an even lower contribution despite the same water flow as technical SSO. This is explained by the relatively good removal efficiency of this partial treatment at WWTPs.

As the presented calculations of microplastic discharge from WWTPs and SSO-events are based on limited available data and sampling occasions for WWTPs, results may inherit a high degree of uncertainty. Total discharges of microplastics from various pathways and related distributions among these might as well been overestimated as underestimated. Depending on data source used, several orders of magnitude in reported microplastic particles illustrate the general variation and uncertainty in this research field. Nevertheless, of encountered uncertainties, the significance of SSO is clearly shown.

\section{Conclusions}

Presented results indicate a considerable discharge of microplastic to recipients of the Baltic Sea from WWTPs, this, despite relatively good overall removal efficiency in existing facilities. Even so, there is room for improvements in some countries; average removal efficiency for microplastics of $93 \%$ must be considered 
as very good and mitigation should focus on other significant sources. The presented results clearly indicate that SSOs are such a significant source with relevance for the total discharge of microplastics to recipients. This despite the relatively small share of total water flows of SSO.

The study shows that the discharge of microplastics from sewer overflows can be in the same magnitude as from treated wastewater although the total flow is much lower than that of treated wastewater. Sewer overflow events frequently occur and are expected to increase due to climate change and urbanization, unless infrastructure is adapted. At the same time, sewer overflows are often neglected in conventional wastewater handling, as traditional pollutant concentrations such as nutrients and organics often are much lower due to dilution with stormwater. For microplastics, however, this does not have to be the case.

The present findings may, therefore, be used to increase focus on mitigation measures on preventing discharge of microplastics to the environment by either reducing the risk for SSOs or by implementing a basic treatment of sewer overflows in similar ways as already done in some WWTPs. For this, the monitoring of SSO events would be required, which also would facilitate for a refinement of the estimated microplastic discharge amounts suggested by this study.

\section{Acknowledgements}

This work resulted from the BONUS MICROPOLL-Multilevel assessment of microplastics and associated pollutants in the Baltic Sea project and was supported by BONUS (Art 185), funded jointly by the EU and VINNOVA.

\section{Conflicts of Interest}

The authors declare no conflicts of interest regarding the publication of this paper.

\section{References}

[1] GESAMP-IOC (2014) Microplastics in the Ocean. IMO/FAO/IOC/WMO/UNIDO/IAEA/UN/UNEP Joint Group of Experts on the Scientific Aspects of Marine Environmental Protection. Paris.

[2] IPBES (2018) Summary for Policymakers of the Regional Assessment Report on Biodiversity and Ecosystem Services for Europe and Central Asia of the Intergovernmental Science-Policy Platform on Biodiversity and Ecosystem Services. In: Fischer, M., Rounsevell, M., Torre-Marin Rando, A., Mader, A., Church, A., Elbakidze, M., Elias, V., Hahn, T., Harrison, P.A., Hauck, J., Martín-López, B., Ring, I., Sandström, C., Sousa Pinto, I., Visconti, P., Zimmermann, N.E. and Christie, M., Eds., IPBES Secretariat, Bonn, Germany, 48 p.

[3] UNEP Yearbook (2014) Emerging Issues in Our Global Environment. UNEP Division of Early Warning and Assessment, United Nations Environment Programme.

[4] Besseling, E., Wang, B., Lürling, M. and Koelmans, A.A. (2014) Nanoplastic Affects Growth of S. obliquus and Reproduction of D. magna. Environmental Science \& Technology, 48, 12336-12343. https://doi.org/10.1021/es503001d

[5] Browne, M.A., Dissanayake, A., Galloway, T.S., Lowe, D.M. and Thompson, R.C. 
(2008) Ingested Microscopic Plastic Translocates to the Circulatory System of the Mussel, Mytilus edulis (L.). Environmental Science \& Technology, 42, 5026-5031. https://doi.org/10.1021/es800249a

[6] Chen, J., Tan, M., Nemmar, A., Song, W., Dong, M., Zhang, G. and Li, Y. (2006) Quantification of Extrapulmonary Translocation of Intratracheal-Instilled Particles in Vivo in Rats: Effect of Lipopolysaccharide. Toxicology, 222, 195-201. https://doi.org/10.1016/j.tox.2006.02.016

[7] Li, J., Liu, H. and Chen, J.P. (2018) Microplastics in Freshwater Systems: A Review on Occurrence, Environmental Effects, and Methods for Microplastics Detection. Water Research, 137, 362-374. https://doi.org/10.1016/j.watres.2017.12.056

[8] Ogonowski, M., Schür, C., Jarsén, Å. and Gorokhova, E. (2016) The Effects of Natural and Anthropogenic Microparticles on Individual Fitness in Daphnia magna. PLoS ONE, 11, e0155063. https://doi.org/10.1371/journal.pone.0155063

[9] Rainieri, S., Conlledo, N., Larsen, B.K., Granby, K. and Barranco, A. (2018) Combined Effects of Microplastics and Chemical Contaminants on the Organ Toxicity of Zebrafish (Danio rerio). Environmental Research, 162, 135-143.

https://doi.org/10.1016/j.envres.2017.12.019

[10] Sussarellu, R., Suquet, M., Thomas, Y., Lambert, C., Fabioux, C., Pernet, M.E.J., Goïc, N.L., Quillien, V., Mingant, C. and Epelboin, Y. (2016) Oyster Reproduction Is Affected by Exposure to Polystyrene Microplastics. Proceedings of the National Academy of Sciences of the United States of America, 113, 2430-2435. https://doi.org/10.1073/pnas.1519019113

[11] Ogonowski, M., Gerdes, Z. and Gorokhova, E. (2018) What We Know and What We Think We Know about Microplastic Effects: A Critical Perspective. Current Opinion in Environmental Science \& Health, 1, 41-46.

[12] Browne, M.A., Niven, S.J., Galloway, T.S., Rowland, S.J. and Thompson, R.C. (2013) Microplastic Moves Pollutants and Additives to Worms, Reducing Functions Linked to Health and Biodiversity. Current Biology, 23, 2388-2392. https://doi.org/10.1016/j.cub.2013.10.012

[13] Rios, L.M., Jones, P.R., Moore, C. and Narayan, U.V. (2010) Quantitation of Persistent Organic Pollutants Adsorbed on Plastic Debris from the Northern Pacific Gyre's "Eastern Garbage Patch". Journal of Environmental Monitoring, 12, 2226-2236. https://doi.org/10.1039/c0em00239a

[14] Talsness, C.E., Andrade, A.J.M., Kuriyama, S.N., Taylor, J.A. and Saal, F.S.V. (2009) Components of Plastic: Experimental Studies in Animals and Relevance for Human Health. Philosophical Transactions of the Royal Society of London, 364, 2079. https://doi.org/10.1098/rstb.2008.0281

[15] Teuten, E.L., Saquing, J.M., Knappe, D.R., Barlaz, M.A., Jonsson, S., Björn, A., Rowland, S.J., Thompson, R.C., Galloway, T.S. and Yamashita, R. (2009) Transport and Release of Chemicals from Plastics to the Environment and to Wildlife. Philosophical Transactions of the Royal Society of London, 364, 2027. https://doi.org/10.1098/rstb.2008.0284

[16] Kay, P., Hiscoe, R., Moberley, I., Bajic, L. and McKenna, N. (2018) Wastewater Treatment Plants as a Source of Microplastics in River Catchments. Environmental Science and Pollution Research, 25, 20264-20267.

https://doi.org/10.1007/s11356-018-2070-7

[17] Mintenig, S.M., Int-Veen, I., Löder, M.G.J., Primpke, S. and Gerdts, G. (2016) Identification of Microplastic in Effluents of Waste Water Treatment Plants Using Focal Plane Array-Based Micro-Fourier-Transform Infrared Imaging. Water Research, 108, 
365-372. https://doi.org/10.1016/j.watres.2016.11.015

[18] Prata, J.C. (2018) Microplastics in Wastewater: State of the Knowledge on Sources, Fate and Solutions. Marine Pollution Bulletin, 129, 262-265.

https://doi.org/10.1016/j.marpolbul.2018.02.046

[19] Roex, E., Vethaak, D., Leslie, H. and Kreuk, M.D. (2013) Potential Risk of Microplastics in the Fresh Water Environment. STOWA Technical Report, Amersfoort.

[20] Ziajahromi, S., Neale, P.A. and Leusch, F.D.L. (2016) Wastewater Treatment Plant Effluent as a Source of Microplastics: Review of the Fate, Chemical Interactions and Potential Risks to Aquatic Organisms. Water Science and Technology, 74, 2253-2269.

[21] Carr, S.A., Liu, J. and Tesoro, A.G. (2016) Transport and Fate of Microplastic Particles in Wastewater Treatment Plants. Water Research, 91, 174-182.

https://doi.org/10.1016/j.watres.2016.01.002

[22] Gies, E.A., LeNoble, J.L., Noël, M., Etemadifar, A., Bishay, F., Hall, E.R. and Ross, P.S. (2018) Retention of Microplastics in a Major Secondary Wastewater Treatment Plant in Vancouver, Canada. Marine Pollution Bulletin, 133, 553-561. https://doi.org/10.1016/j.marpolbul.2018.06.006

[23] Magnusson, K., Jörundsdóttir, H., Norén, F., Lloyd, H., Talvitie, J. and Setälä, O. (2016) Microlitter in Sewage Treatment Systems, TemaNord. Nordic Council of Ministers, Copenhagen. https://doi.org/10.6027/TN2016-510

[24] Murphy, F., Ewins, C., Carbonnier, F. and Quinn, B. (2016) Wastewater Treatment Works (WwTW) as a Source of Microplastics in the Aquatic Environment. Environmental Science \& Technology, 50, 5800-5808.

https://doi.org/10.1021/acs.est.5b05416

[25] Sun, J., Dai, X., Wang, Q., van Loosdrecht, M.C.M. and Ni, B.-J. (2019) Microplastics in Wastewater Treatment Plants: Detection, Occurrence and Removal. Water Research, 152, 21-37. https://doi.org/10.1016/j.watres.2018.12.050

[26] Talvitie, J., Mikola, A., Koistinen, A. and Setälä, O. (2017) Solutions to Microplastic Pollution-Removal of Microplastics from Wastewater Effluent with Advanced Wastewater Treatment Technologies. Water Research, 123, 401-407. https://doi.org/10.1016/j.watres.2017.07.005

[27] Dris, R., Gasperi, J. and Tassin, B. (2018) Sources and Fate of Microplastics in Urban Areas: A Focus on Paris Megacity. In: Wagner, M. and Lambert, S., Eds., Freshwater Microplastics, Springer International Publishing, Cham, 69-83. https://doi.org/10.1007/978-3-319-61615-5_4

[28] WATERBASE (2019) Waterbase-UWWTD: Urban Waste Water Treatment Directive-Reported Data.

https://www.eea.europa.eu/data-and-maps/data/waterbase-uwwtd-urban-waste-wat er-treatment-directive-5

[29] HELCOM (2019) http://maps.helcom.fi/website/mapservice/index.html

[30] SMP (2019) Svenska Miljörapporteringsportalen. https://smp.lansstyrelsen.se/Default.aspx

[31] Ministry of Environment and Food of Denmark (2019) Punktkilder 2015. Styrelsen for Vand- og Naturforvaltning.

[32] Baresel, C., Ek, M., Ejhed, H., Allard, A.-S., Magnér, J., Dahlgren, L., Westling, K., Wahlberg, C., Fortkamp, U. and Söhr, S. (2017) Handbok för rening av mikroföroreningar vid avloppsreningsverk-Planering och installation av reningstekniker för läkemedelsrester och andra mikroföroreningar. Slutrapport SystemLäk projekt. 
IVL Svenska Miljöinstitutet, Rapport B2288.

[33] StatA, M.-V. (2013) Statistischer Bericht Q113 201301.

[34] Magnusson, K. and Wahlberg, C. (2014) Mikroskopiska skräppartiklar i vatten från avloppsreningsverk. IVL Swedish Environmental Research Institute, Report B2208.

[35] Talvitie, J., Mikola, A., Setälä, O., Heinonen, M. and Koistinen, A. (2016) How Well Is Microlitter Purified from Wastewater?: A Detailed Study on the Stepwise Removal of Microlitter in a Tertiary Level Wastewater Treatment Plant. Water Research, 109, 164-172. https://doi.org/10.1016/j.watres.2016.11.046

[36] Magnusson, K. and Norén, F. (2014) Screening of Microplastic Particles in and DownStream a Wastewater Treatment Plant. IVL Swedish Environmental Research Institute, Report C55.

[37] Magnusson, K., Fråne, A., Haikonen, K., Hultén, J., Olshammar, M., Stadmark, J. and Voisin, A. (2016) Swedish Sources and Pathways for Microplastics to the Marine Environment: A Review of Existing Data. IVL Swedish Environmental Research Institute.

[38] Simon, M., van Alst, N. and Vollertsen, J. (2018) Quantification of Microplastic Mass and Removal Rates at Wastewater Treatment Plants Applying Focal Plane Array (FPA)-Based Fourier Transform Infrared (FT-IR) Imaging. Water Research, 142, 1-9. https://doi.org/10.1016/j.watres.2018.05.019

[39] Siegfried, M., Koelmans, A.A., Besseling, E. and Kroeze, C. (2017) Export of Microplastics from Land to Sea. A Modelling Approach. Water Research, 127, 249-257. https://doi.org/10.1016/j.watres.2017.10.011

[40] Gävleborg, L. (2009) Bräddning av avloppsvatten i Sverige och Gävleborgs län, R 2009:1.

[41] Sjörs, Å.B. (2014) Bräddning från ledningsnät-Vägledning för att kontrollera, rapportera och bedöma miljöbelastning på recipient. Svenskt Vatten Utveckling Nr 2014-01. 